\title{
Effectiveness of integrated nursing interventions for fatigue in patients with advanced cancer: a systematic review of randomized controlled trials
}

Original article

Xiao-Lin Zuo ${ }^{a}$, Yan Wena, Shang-Qun Gong ${ }^{b}$, Fan-Jie Meng, **

${ }^{a}$ Department of Nursing, The Central Hospital of Luohe (the First Affiliated Hospital of Luohe Medical College), Luohe, Henan 462000, China

${ }^{b}$ Tianjin University of Traditional Chinese Medicine, Tianjin 300193, China

Received: 17 July 2018; Accepted: 23 December 2018; Published: 20 September 2019

Abstract: Objective: To evaluate the effectiveness of integrated nursing interventions for fatigue in patients with advanced cancer.

Methods: Medline, Pubmed, Embase, CINAHL, Web of Science, and the Cochrane Library were searched systematically till June 2017. A systematic review was conducted to collect randomized controlled trials (RCTs) reporting on the effect of nurse-driven interventions to improve fatigue in patients with advanced cancer. Quality assessment was conducted using the Cochrane Collaboration's risk of bias tool.

Results: Six RCTs involving 736 adult participants were included. The fatigue intensity was improved significantly by nursing interventions. The analyzed results revealed significant improvements in the intervention group: less than 3 months (standard mean difference $[\mathrm{SMD}]=-0.33,95 \%$ confidence interval $[\mathrm{CI}][-0.48,-0.19], P<0.01$ ) and more than or equal to 3 months $(\mathrm{SMD}=-0.40,95 \% \mathrm{Cl}[-0.57,-0.24], P<0.01)$. Four studies with a moderate risk of bias were judged, and the remaining studies were at high risk of bias.

Conclusions: The results indicate that integrated nursing interventions may relieve fatigue in patients with advanced cancer. However, due to the high risk of bias in most of the included studies and the diversity of interventions, the results and implementation process should be carefully monitored.

Keywords: fatigue $\bullet$ neoplasms $\bullet$ nurses $\bullet$ palliative care $\bullet$ advanced $\bullet$ evidence-based nursing $\bullet$ systematic review $\bullet$ hospice and palliative care nursing

(c) Shanxi Medical Periodical Press.

\section{Introduction}

Fatigue is associated with a high prevalence of multicausal symptom in patients with terminal cancer, which is classically defined as a distressing, persistent, subjective sense of tiredness or exhaustion related to cancer. ${ }^{1}$ Cancer-related fatigue can decrease patients' activity level resulting in the loss of muscle mass and reduced cardiac output, which can leave patients in a deconditioned state. ${ }^{2}$ Moreover, fatigue can lead to negative emotions and spiritual distress, sleep disturbances, and treatment noncompliance for both patients with cancer and their family members. ${ }^{3}$

Pharmacotherapy is rarely adequate, and the safe and effective interventions against fatigue in these patients are needed. Recently, a growing number of

How to cite this article: Zuo XL, Wen Y, Gong SQ, Meng FJ. Effectiveness of integrated nursing interventions for fatigue in patients with advanced cancer: a systematic review of randomized controlled trials. Front Nurs. 2019; 3: $203-210$. 
investigators have been chosen to develop interventions delivered by nurses to address fatigue, which have been shown to be promising. These nursing interventions have advantages in relieving fatigue for both short- and long-term periods. Although these studies illuminate the evidence in their respective areas, to our knowledge, no integrated reviews have been carried out so far.

\section{Methods}

\subsection{Inclusion criteria}

The searching format was applied to address the research question and establish eligibility criteria. The diagnosis of fatigue in patients with cancer includes the following: (1) self-reported fatigue: patients report fatigue as a state of physical disturbance and loss of function, with exhaustion being the lead factor in reduced physical activity; ${ }^{4}$ (2) diagnosed by questionnaires: brief assessment tools such as the Numeric Rating Scale of fatigue and the Edmonton Symptom Assessment Scale of fatigue.

\subsection{Search methods}

Studies were identified by searching Medline, Pubmed, Embase, CINAHL, Web of Science, and the Cochrane Library from the inception of databases to June 2017. We used MeSH terms and all fields when searching. The search strategy was as follows: ("Neoplasms" [MeSH] or "Carcinoma" [MeSH] or "cancer" or "oncology" or "malignant") and ("advanced" OR "incurable" OR "metastasized" OR "terminal" OR "late stage") and ("Nurses" [MeSH] or"nurse*" or "nurs*" or "care") and ("Fatigue" [Mesh] OR "Mental fatigue" [Mesh]) and ("randomized controlled trial" or "random allocation" or "double-blind method" or "single-blind method").

\subsection{Study selection}

One reviewer screened the study on the basis of title and abstract. If any doubtable information existed, the articles were included in the full-text screening phase. The full texts of candidate articles were screened by two independent reviewers. Any disagreement was discussed with additional reviewer. Inclusion criteria were as follows: (1) participants: adults with advanced cancer aged 18 years or older; patients with recurrent cancer and who were undergoing chemotherapy or undergoing radiotherapy were also included; (2) intervention: nonpharmacological interventions driven by nurses aimed at managing fatigue due to cancer or cancer treatment; (3) comparator: any comparator; (4) outcomes: fatigue measured by authorized measurements; (5) study design: randomized controlled trials (RCTs) published in
English in a peer-reviewed journal. We excluded quasiRCT studies, studies without full texts, and duplicates.

\subsection{Quality assessment}

The quality assessment of the selected studies was conducted independently using the Cochrane Collaboration's tool. Any disagreement between reviewers was resolved through discussion or consultation with a third reviewer.

The quality items checked were the following: sequence generation, allocation concealment, blinding, incomplete data outcomes, selective outcome reporting, and other biases, in which each of the components can be rated as low, unclear, or high risk of bias.

\subsection{Data collection process and synthesis}

Data extraction was performed independently by two authors. As a result, the details of the extracted data were as follows: the first author's name and publication year; detailed characteristics of interventions; participants (country and setting, diagnose, sample size, age, and gender); and outcome measures, follow-up, and main results. Continuous outcomes were compared using standard mean differences (SMDs) and a 95\% confidence interval $(\mathrm{Cl})$ with a fixed-effect model. If statistical pooling was not appropriate, findings were collected in tables and described narratively.

\section{Results}

\subsection{Study selection}

The flowchart of the selection of eligible studies is shown in Figure 1.

The initial search yielded 1752 original articles. Three additional articles were identified after checking the reference lists which resulted in a total of 1755 articles. After the removal of duplicates, 1670 studies were screened for inclusion based on titles and abstracts. Of these, the full text of the remaining 52 studies was assessed. It was found that seven were not related to patients with advanced cancer, 26 did not focus on nursing interventions, eleven were non-RCTs, and two had duplicate data. We e-mailed the corresponding author to ask for the available outcome data, and six studies were included in the review eventually. ${ }^{5-10}$

\subsection{Outcome analyses}

All patients in the studies were already experiencing fatigue at baseline, and different tools were used in the studies to measure fatigue including the following: patientreported measures: Functional Assessment of Cancer 


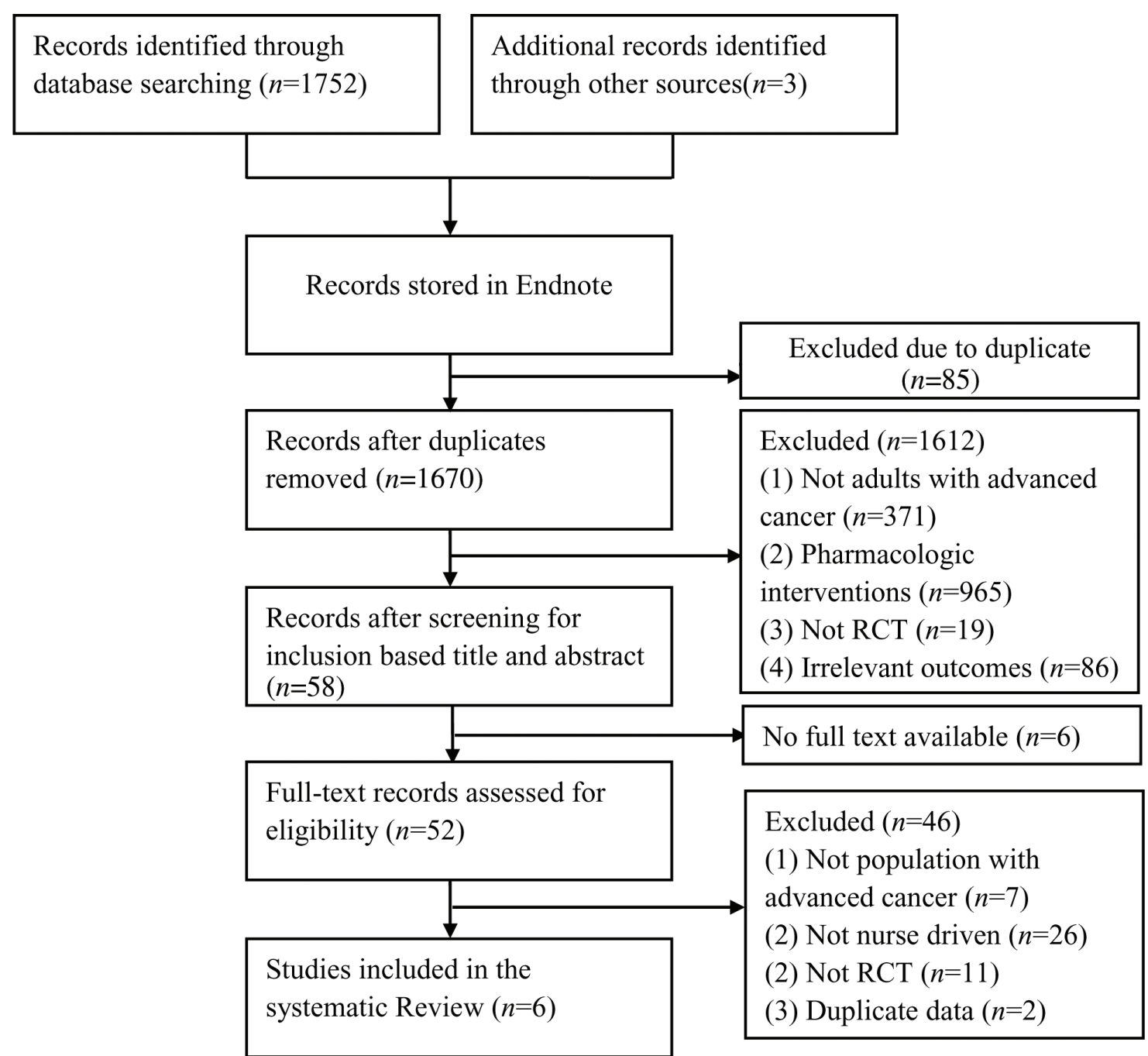

Figure 1. PRISMA flowchart of selection process.

Therapy-Fatigue (FACT-F) scale, Brief Fatigue Inventory (BFI), Multidimensional Fatigue Inventory (MFI), and the revised Piper Fatigue Scale; clinician-assessed measures: muscular strength. The analyzed results revealed significant improvements in the intervention group: less than 3 months $(\mathrm{SMD}=-0.33,95 \% \mathrm{Cl}(-0.48$, $-0.19), P<0.01)$ and more than or equal to 3 months $(\mathrm{SMD}=-0.40,95 \% \mathrm{Cl}(-0.57,-0.24), P<0.01$; Figure 2$)$. In addition, significant improvements in muscular strength were seen in favor of the intervention group.

\subsection{Quality appraisal}

The risk of bias was assessed using the Cochrane Collaboration tool, and it is shown in Figure 3.

In two studies, 5,6 the allocation sequence was adequately generated and concealed by drawing lots from opaque envelopes or sealed boxes. The method of concealment of allocation was not fully reported in the remaining studies; therefore, the risk of bias was unclear. All trials had adequate random generation by flipping a coin or computer-generated schedule. Only one trial ${ }^{7}$ reported blinding of participants. Three of the trials reported assessor blinding.$^{6-8}$ With a loss to follow up ranging between $0 \%$ and $35 \%$, attrition was problematic in the majority of the studies. Two studies ${ }^{6,8}$ reported missing outcome data which balanced in numbers between the intervention group and control group. The remaining did not mention the reason for missing data and did not carry out intention-to-treat analysis, which led to attrition bias. Patients did not complete the study mainly due to disease progression or death. All six studies adequately reported the results (fatigue scores as primary outcome). Considering other biases, all trials had adequately matched participants in the two groups and were free from baseline imbalance bias. For early 


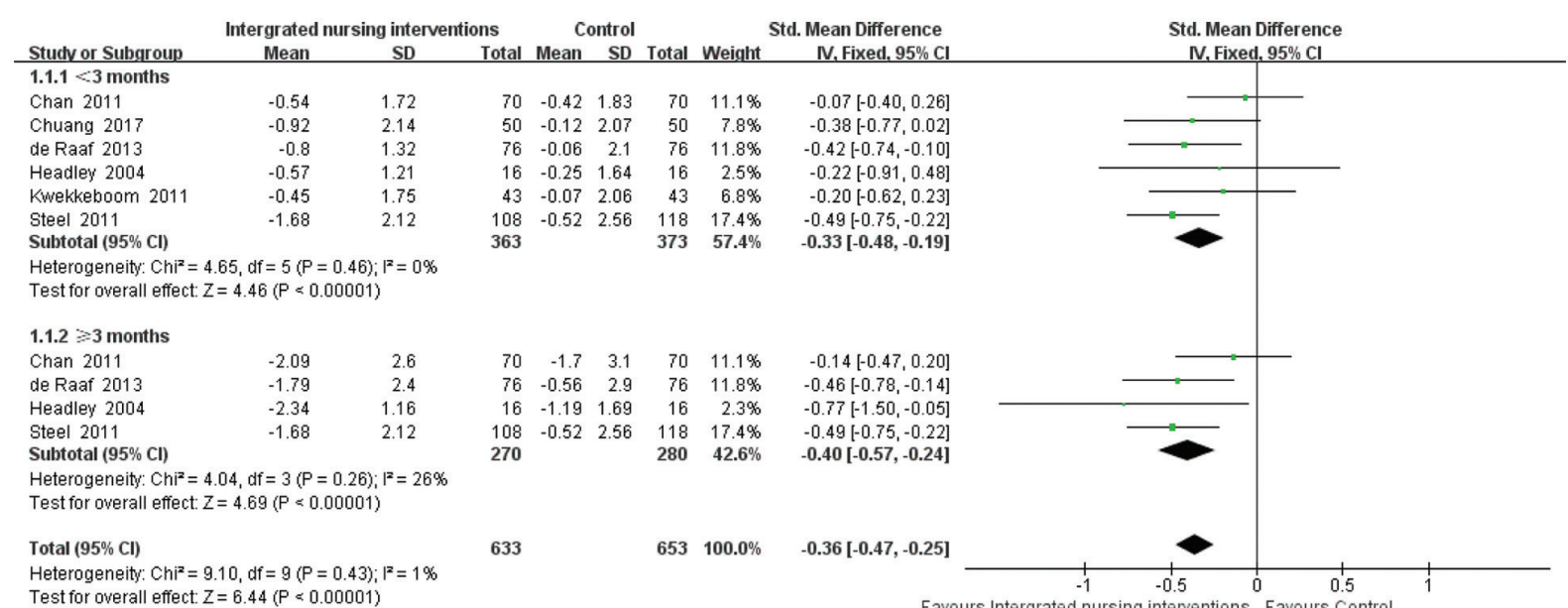

Favours Intergrated nursing interventions Favours Control

Figure 2. Forest plots of pooled results for integrated nursing interventions on fatigue in patients with advanced cancer.

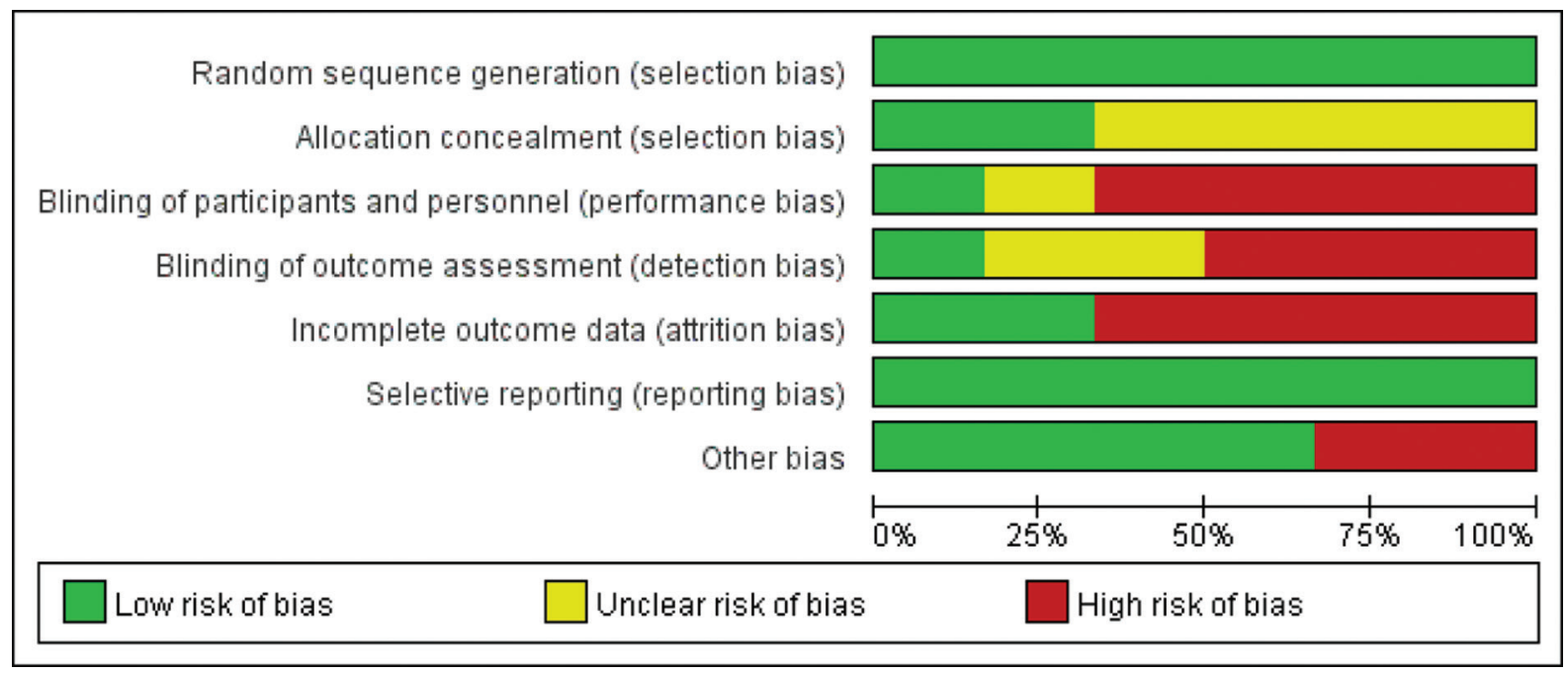

Figure 3. Summary risk of bias.

stopping, none of the six trials were stopped in advance. The source of funding bias was unclear in the trials by Chan et al. ${ }^{10}$ and Headley et al..$^{8}$ The sources of funding in other studies were academic medical or social science foundations, and we considered the trials to be free from risk of source of funding bias.

All studies had at least two risks of bias. The four trials $^{5-8}$ received overall moderate risk of bias, and the others received high risk of bias.

\subsection{Study characteristics}

The characteristics of these studies are summarized in Table 1. The characteristics of the included studies are summarized in Table 2.
Total sample size in terms of the number of patients was given in all of the studies and ranged from 38 to 226, and the pooled sample size was 736 (intervention group $=363$, control group $=373$ ). The included studies were conducted in the USA, the Netherlands, Hong Kong, and Taiwan. The publication year range of the included studies spreads over a considerable period from 2004 to 2017.

The nurse interventions in the six studies were varied, including stepped collaborative care intervention, protocolized patient-tailored care, psychoeducation, seated exercise, cognitive behavior, and qigong program. The studies did not compare any treatment or usual care. Usual care in the trials included routine medical care from the nurse and attending physician. 


\begin{tabular}{|c|c|c|c|c|c|c|}
\hline Studies & Country/setting & Study sample & Intervention & Control & $\begin{array}{l}\text { Measurement } \\
\text { tools and time } \\
\text { points }\end{array}$ & Results \\
\hline Steel et al. ${ }^{5}$ & $\begin{array}{l}\text { USA/a large } \\
\text { tertiary cancer } \\
\text { center }\end{array}$ & $\begin{array}{l}226 \text { advanced liver cancer } \\
\text { patients } \\
\text { I: } n=108 ; C: n=118 \\
\text { Age: } 18 \text { years or older }\end{array}$ & $\begin{array}{l}\text { Stepped } \\
\text { collaborative } \\
\text { care }\end{array}$ & $\begin{array}{l}\text { Usual } \\
\text { care }\end{array}$ & $\begin{array}{l}\text { FACT-F, } \\
\text { baseline, and } \\
\text { at } 2,4 \text {, and } 6 \\
\text { months }\end{array}$ & $\begin{array}{l}\text { The fatigue score } \\
\text { was greatly } \\
\text { reduced in the } \\
\text { intervention group* }\end{array}$ \\
\hline $\begin{array}{l}\text { Kwekkeboom } \\
\text { et al. }{ }^{6}\end{array}$ & $\begin{array}{l}\text { USA/a } \\
\text { comprehensive } \\
\text { cancer center }\end{array}$ & $\begin{array}{l}86 \text { advanced lung, prostate, } \\
\text { colorectal, or gynecologic } \\
\text { cancers } \\
\text { I: } n=43 \text { ( } 14 \text { males); age: } \\
60.4 \pm 10.8 \text { years } \\
\text { C: } n=43 \text { ( } 21 \text { males); age: } \\
60.1 \pm 11.5 \text { years }\end{array}$ & $\begin{array}{l}\text { Cognitive } \\
\text { behavior }\end{array}$ & $\begin{array}{l}\text { Waitlist } \\
\text { control }\end{array}$ & $\begin{array}{l}\text { BFI, baseline, } \\
\text { and at } 2 \text { weeks } \\
\text { later }\end{array}$ & $\begin{array}{l}\text { The intervention } \\
\text { group reported } \\
\text { less fatigue at } \\
2 \text { weeks than the } \\
\text { control group* }\end{array}$ \\
\hline Chuang et al. ${ }^{7}$ & $\begin{array}{l}\text { Taiwan/ } \\
\text { Departments of } \\
\text { Oncology and } \\
\text { Hematology }\end{array}$ & $\begin{array}{l}100 \text { advanced cancer patients } \\
\text { I: } n=50 \text { ( } 24 \text { males); age: } \\
47.2 \pm 10.7 \text { years } \\
\text { C: } n=50 \text { ( } 29 \text { males); age: } \\
47.2 \pm 10.6 \text { years }\end{array}$ & $\begin{array}{l}\text { Chan-Chuang } \\
\text { qigong }\end{array}$ & $\begin{array}{l}\text { Usual } \\
\text { care }\end{array}$ & $\begin{array}{l}\text { BFI and } \\
\text { muscular } \\
\text { strength, } \\
\text { baseline, and at } \\
21 \text { days later }\end{array}$ & $\begin{array}{l}\text { The fatigue score } \\
\text { was greatly } \\
\text { reduced in the } \\
\text { intervention } \\
\text { group* }\end{array}$ \\
\hline Headley et al. ${ }^{8}$ & $\begin{array}{l}\text { USA/outpatient } \\
\text { clinic of a } \\
\text { comprehensive } \\
\text { cancer center }\end{array}$ & $\begin{array}{l}38 \text { patients with advanced } \\
\text { breast cancer who were } \\
\text { started to undergo outpatient } \\
\text { chemotherapy. } \\
\text { I: } n=16 \text {; age: } 52.25 \pm 11.43 \text { years } \\
\text { C: } n=16 \text {; age: } 50.0 \pm 7.10 \text { years }\end{array}$ & Seated exercise & $\begin{array}{l}\text { Usual } \\
\text { physical } \\
\text { activity }\end{array}$ & $\begin{array}{l}\text { FACT-F, } \\
\text { baseline, and at } \\
\text { the beginning } \\
\text { of next three } \\
\text { chemotherapy } \\
\text { cycles }\end{array}$ & $\begin{array}{l}\text { FACT-F scores } \\
\text { declined at a } \\
\text { significant rate* }\end{array}$ \\
\hline de Raaf et al. ${ }^{9}$ & $\begin{array}{l}\text { The Netherlands/ } \\
\text { outpatient } \\
\text { clinic of a } \\
\text { comprehensive } \\
\text { cancer center }\end{array}$ & $\begin{array}{l}152 \text { advanced cancer patients } \\
\text { I: } n=76 \text { ( } 31 \text { males); age: } \\
57 \pm 9.7 \text { years } \\
\text { C: } n=76 \text { ( } 34 \text { males); age: } \\
59 \pm 10.5 \text { years }\end{array}$ & $\begin{array}{l}\text { Protocolized } \\
\text { patient-tailored } \\
\text { care }\end{array}$ & $\begin{array}{l}\text { Usual } \\
\text { care }\end{array}$ & $\begin{array}{l}\text { MFI, baseline } \\
\text { and, at } 1,2 \text {, } \\
3 \text { months }\end{array}$ & $\begin{array}{l}\text { The intervention } \\
\text { group revealed } \\
\text { significant } \\
\text { improvements in } \\
\text { managing fatigue* }\end{array}$ \\
\hline Chan et al. ${ }^{10}$ & $\begin{array}{l}\text { Hong Kong/ } \\
\text { outpatient clinic } \\
\text { of a publicly } \\
\text { funded hospital }\end{array}$ & $\begin{array}{l}140 \text { advanced (stage } 3 \text { or } 4 \text { ) } \\
\text { lung cancer patients } \\
\text { I: } n=70 \text { ( } 58 \text { males) C: } n=70 \\
\text { ( } 58 \text { males) } \\
\text { Age: } 18 \text { years or older }\end{array}$ & Psychoeducation & $\begin{array}{l}\text { Usual } \\
\text { care }\end{array}$ & $\begin{array}{l}\text { The revised } \\
\text { Piper Fatigue } \\
\text { Scale, baseline, } \\
\text { and at } 3,6 \text {, and } \\
12 \text { weeks later }\end{array}$ & $\begin{array}{l}\text { The fatigue score } \\
\text { was greatly } \\
\text { reduced in the } \\
\text { intervention } \\
\text { group* }\end{array}$ \\
\hline
\end{tabular}

Note: *: P<0.05; I: Intervention group; C: Control group; BFI, Brief Fatigue Inventory; FACT-F, Functional Assessment of Cancer Therapy-Fatigue; $\mathrm{MFI}$, Multidimensional Fatigue Inventory.

Table 1. Characteristics of the study instruments and samples.

Except the studies such as Chuang et al., ${ }^{7}$ Headley et al., ${ }^{8}$ and de Raaf et al.., ${ }^{9}$ the remaining studies were all conducted based on protocols. Only Chan et al. ${ }^{10}$ provided full access protocol online. For the intervention, the session of intervention varied between 20 and 60 minutes each time. The studies correspondingly had the least and most number of interventions of 4 and 40 sessions, respectively. Contacts between patient and nurse were face to face, telephone, or mixed.

Interventions were delivered by clinical nurses, research nurses, and nurse coordinators, and all nurses followed a training session. Nurse-coordinated interventions were conducted in the studies by Steel et al. ${ }^{5}$ and Chuang et al., ${ }^{7}$ one with psychologists and the other with physiotherapists. Regarding the delivery form, interventions were conducted individually, in groups, or combination of both.

\subsection{Adverse event in nurse practicing}

None of the researchers reported any adverse effects due to the interventions.

\section{Discussion}

Six studies met the inclusion criteria. The varied nursing interventions were categorized into stepped collaborative care, protocolized patient-tailored care, psychoeducation, seated exercise, cognitive behavior, and qigong program. The meta-analysis results showed significant improvement in fatigue with nurse-driven interventions, while due to a small number of studies the results and implementation process should be carefully monitored.

Effective management of fatigue requires comprehensive interdisciplinary care. ${ }^{11}$ As Steel et al. ${ }^{5}$ advised, the collaborative care team included nurses coordinators, physicians, psychologists, and most importantly, patients and their caregivers, all worked together as a team. The team was formed to monitor patients during treatment and to assess as well as treat symptoms via online. Nurse coordinators played a key role to monitor fatigue level by phone calls. Tele-monitoring, such as Web-based interventions, has been recommended to patients with advanced cancer who may not have access to traditional face-to-face treatments and reduce health care cost. ${ }^{5,12}$ Similarly, a study used palliative 


\begin{tabular}{|c|c|c|c|c|c|}
\hline Studies & Intervention performers & $\begin{array}{l}\text { Adherence to delivery } \\
\text { protocols }\end{array}$ & $\begin{array}{l}\text { Duration and } \\
\text { intensity }\end{array}$ & $\begin{array}{l}\text { Patient } \\
\text { adherence }\end{array}$ & $\begin{array}{l}\text { Summary of intervention } \\
\text { content }\end{array}$ \\
\hline Steel et al. ${ }^{5}$ & $\begin{array}{l}\text { Nurse coordinators and } \\
\text { psychologists }\end{array}$ & $\begin{array}{l}\text { Trained telephone } \\
\text { interviewers follow } \\
\text { a structured clinical } \\
\text { interview }\end{array}$ & 60 minutes & Telephone & $\begin{array}{l}\text { Education, self-management, } \\
\text { journaling, a chat room, an } \\
\text { audiovisual library, and peer } \\
\text { support }\end{array}$ \\
\hline Kwekkeboom et al. ${ }^{6}$ & A research nurse & $\begin{array}{l}\text { Training sessions } \\
\text { were audio-recorded } \\
\text { and intervention } \\
\text { fidelity was assessed } \\
\text { with a checklist }\end{array}$ & $\begin{array}{l}\text { A start and a final } \\
\text { study meeting. } \\
\text { Patients were } \\
\text { encouraged to } \\
\text { practice at least } \\
\text { once per day for } \\
\text { approximately } \\
20 \text { minutes long } \\
\text { for } 2 \text { weeks during } \\
\text { cancer treatment }\end{array}$ & $\begin{array}{l}\text { Diary, } \\
\text { telephone, and } \\
\text { mail }\end{array}$ & $\begin{array}{l}\text { Relaxation, imagery, or } \\
\text { distraction exercises via an } \\
\text { educational booklet and } \\
\text { MP3 player }\end{array}$ \\
\hline Chuang et al. ${ }^{7}$ & $\begin{array}{l}\text { Nurse specialists and } \\
\text { physiotherapists }\end{array}$ & No data & $\begin{array}{l}21 \text { days in addition } \\
\text { to conventional care }\end{array}$ & $\begin{array}{l}\text { Training } \\
\text { session }\end{array}$ & $\begin{array}{l}\text { Relaxation, body awareness, } \\
\text { and qigong training }\end{array}$ \\
\hline Headley et al. ${ }^{8}$ & Nursing specialists & No data & $\begin{array}{l}\text { A } 30 \text {-minute seated } \\
\text { exercise program } \\
\text { three times a week } \\
\text { with at least 1-day } \\
\text { break between } \\
\text { sessions }\end{array}$ & $\begin{array}{l}\text { Monthly } \\
\text { calendar log }\end{array}$ & $\begin{array}{l}\text { Five-minute warm-up, } \\
20 \text { minutes of moderate- } \\
\text { intensity repetitive motion } \\
\text { exercises, and 5-minute } \\
\text { cooldown }\end{array}$ \\
\hline de Raaf et al. ${ }^{9}$ & Nurse specialists & No data & $\begin{array}{l}\text { Train meetings within } \\
1 \text { week after random } \\
\text { assignment, after } \\
2-4 \text { weeks, after } \\
5-7 \text { weeks, and after } \\
\text { 8-10 weeks }\end{array}$ & Mail & $\begin{array}{l}\text { Education and non- } \\
\text { pharmacological interventions }\end{array}$ \\
\hline Chan et al. ${ }^{10}$ & $\begin{array}{l}\text { Registered nurses } \\
\text { with } 2 \text { years of clinical } \\
\text { experience }\end{array}$ & $\begin{array}{l}\text { A 2-day training } \\
\text { session focusing } \\
\text { on the educational } \\
\text { package and } \\
\text { progressive muscle } \\
\text { relaxation }\end{array}$ & $\begin{array}{l}\text { A 40-minute } \\
\text { educational package } \\
\text { plus coaching of } \\
\text { progressive muscle } \\
\text { relaxation }\end{array}$ & $\begin{array}{l}\text { Telephone and } \\
\text { diary }\end{array}$ & $\begin{array}{l}\text { Leaflets and discussion on the } \\
\text { selected symptoms and their } \\
\text { self-care management }\end{array}$ \\
\hline
\end{tabular}

Table 2. Characteristics of interventions.

consultation team, where registered nurses were working as practitioner and counselor in fatigue management. ${ }^{13}$ The above two studies revealed significant reduction in fatigue distress in patients with advanced cancer. Nurses employed to do screening, assessment, education, and follow-up adherence in the team and discuss the findings with the specific team members. ${ }^{14}$ The team care should follow a standardized management manual or protocol. ${ }^{15}$

The negative effects of bed rest are well known which possibly induce a vicious cycle between inactivity and intensified fatigue. ${ }^{16,17}$ Thus, recent research suggested a balance between activity and rest that could reduce fatigue particularly in the late stage of cancer. ${ }^{18}$ Thus, nurses must be well trained and tailored to addressing populations' exercise tolerance and potential effects on fatigue management. ${ }^{19}$ Chuang et al. ${ }^{7}$ used the qigong program including body awareness training, relaxation, and massage for patients undergoing chemotherapy, which showed broad effects on fatigue and muscular strength. Similarly, Headley et al. ${ }^{8}$ advised that terminal cancer survivors may much benefit from exercising in a chair in the safety and comfort home setting. Depression was significantly related to fatigue in several studies..$^{7,8}$
Chan et al. ${ }^{10}$ also used psychoeducation for cluster symptoms (fatigue, anxiety, and breathlessness) in advanced lung cancer, which proved a promising results; however, the attrition was problematic in this study. Thus, duplication in intervention should be carefully monitored. Kwekkeboom et al. ${ }^{6}$ proved that relaxation, imagery, and distraction are very useful components in cognitive behaviors; those practices could build peaceful or comfortable experiences for listeners and are used them to treat fatigue effectively. ${ }^{6}$ Overall, nurses with standard training in cognitive intervention could help patients alleviate symptom distress and improve a lot of symptoms particularly fatigue. ${ }^{20-22}$

We recommend that effective and feasible interventions to improve fatigue in patients with late-stage cancer should be practiced in addition to five criteria: (1) practicing tailored to the patient. Nurses should build individualized programs according to the patient (such as current level of energy, tolerance, psychological functions, preferences, expectations, and motivation) and the advanced cancer (treatments and remaining lifetime); $5,9,17$ (2) long-term intervention. The effects of fatigue alleviation would be transient unless the 
intervention is continued, especially cognitive behavior. ${ }^{6}$ Thus, patients should continue using the skills to manage fatigue although the intervention is done. ${ }^{23}$ de Raaf et al. ${ }^{9}$ also argued that these eligible interventions should be part of the routine treatment of fatigue. (3) Optimizing patient adherence: the dropout rates were relatively high among the included researches. Steel et al. ${ }^{5}$ proved that patients who did not complete the study were significantly more likely to report higher fatigue severity. In the included studies, the usual formats of follow up included diary, telephone, e-mail, and log. Particularly, telephone call was perceived by patients with advanced cancer as helpful for symptom management, assessment of negative effects, and promotion of self-management. ${ }^{24}$ Headley et al. ${ }^{8}$ reported that patients and caregivers welcome nursing telephone as a way to maintain contact with nurses, where patients may feel they are receiving care and have a positive effect on outcomes eventually; (4) caregiver involvement. de Raaf et al. ${ }^{9}$ suggested that allowing caregivers to receive interventions may help improve outcomes. Because patients with advanced cancer usually need caregiver's assistance, caregiver can assist patients and promptly remind them when they experience fatigue. ${ }^{11}$ (5) Ensuring the safety: although none of the researchers in the six trials reported any adverse effects caused by nurse-driven programs, patients with advanced cancer reported many uncertain factors; for several skilled interventions such as cognitive behavior and exercise, nurses should be well trained or practiced under the professional supervision. ${ }^{25,26}$ Chuang et al. ${ }^{7}$ also advised to increase the need for daily pre-exercise screening and training sphygmomanometer to ensure safety. Overall, feasible screening, tailored practicing, professional skill, and close monitoring are essential factors to prevent serious adverse events during intervention. ${ }^{27}$

Several limitations of this study require caution in interpreting the results. First, although the authors tried to include many articles, non-English and unpublished studies were excluded from the review, which might

\section{References}

1. Kilgour RD, Vigano A, Trutschnigg B, et al. Cancerrelated fatigue: the impact of skeletal muscle mass and strength in patients with advanced cancer. J Cachexia Sarcopenia Muscle. 2010;1:177-185.

2. Barnes EA, Bruera E. Fatigue in patients with advanced cancer: a review. Int J Gynecol Cancer. 2002;12:424-428.

3. Rao AV, Cohen HJ. Fatigue in older cancer patients: etiology, assessment, and treatment. Semin Oncol. 2008;35:633-642. present a selection bias. Second, the sample size in each research was small. Third, the quality of some studies was relatively low, especially, the attrition rates were high in several studies. Finally, the outcomes of fatigue were measured mainly by patient-reported scales. A survey revealed that patients with advanced cancer were not receiving the help they need..$^{12}$ Thus, better symptom identification and management are warranted for these patients, especially, the optimal method or frequency of screening and practicing for fatigue is essential. Cost-effectiveness is another important outcome to address in the future trials. The included interventions could be considered as a part of standard care in the future trials. Finally, future studies should have a higher methodological quality.

\section{Conclusions}

Integrated nursing interventions in this systematic review included stepped collaborative care, protocolized patient-tailored care, psychoeducation, seated exercise, cognitive behavior, and qigong program. However, because of the overall low quality of the included studies, the results and replication of the interventions need to be taken care. Despite limitations, these findings suggest that the interventions could be complementary approaches for improving fatigue in these patients, with varying potential clinical significance. We also concluded that there are five criteria along with interventions to improve fatigue in patients with terminal cancer. More well-conducted RCTs with lager sample sizes are needed.

\section{Ethics approval}

Not declared.

\section{Conflicts of interest}

All contributing authors declare no conflicts of interest.
4. Kelly DF, Faught WJ, Holmes LA. Ovarian cancer treatment: the benefit of patient telephone follow-up post-chemotherapy. Can Oncol Nurs J. 1999;9:175-178.

5. Steel J, Geller DA, Tsung A, et al. Randomized controlled trial of a collaborative care intervention to manage cancer-related symptoms: lessons learned. Clin Trials. 2011;8:298-310.

6. Kwekkeboom KL, Abbott-Anderson K, Cherwin C, Roiland R, Serlin RC, Ward SE. Pilot randomized 
controlled trial of a patient-controlled cognitivebehavioral intervention for the pain, fatigue, and sleep disturbance symptom cluster in cancer. J Pain Symptom Manage. 2012;44:810-822.

7. Chuang TY, Yeh ML, Chung YC. A nurse facilitated mind-body interactive exercise (Chan-Chuang qigong) improves the health status of non-Hodgkin lymphoma patients receiving chemotherapy: randomised controlled trial. Int J Nurs Stud. 2017; 69:25-33.

8. Headley JA, Ownby KK, John LD. The effect of seated exercise on fatigue and quality of life in women with advanced breast cancer. Oncol Nurs Forum. 2004;31:977-983.

9. de Raaf PJ, de Klerk C, Timman R, Busschbach $\mathrm{JJ}$, Oldenmenger WH, van der Rijt CC. Systematic monitoring and treatment of physical symptoms to alleviate fatigue in patients with advanced cancer: a randomized controlled trial. J Clin Oncol. 2013;31:716-723.

10. Chan CW, Richardson A, Richardson J. Managing symptoms in patients with advanced lung cancer during radiotherapy: results of a psychoeducational randomized controlled trial. J Pain Symptom Manage. 2011; 41:347-357.

11. Chien $\mathrm{CH}$, Liu KL, Chien HT, Liu HE. The effects of psychosocial strategies on anxiety and depression of patients diagnosed with prostate cancer: a systematic review. Int J Nurs Stud. 2014;51:28-38.

12. Johnsen AT, Petersen MA, Pedersen L, Houmann LJ, Groenvold M. Do advanced cancer patients in Denmark receive the help they need? A nationally representative survey of the need related to 12 frequent symptoms/problems. Psychooncology. 2013;22:1724-1730.

13. Winningham ML. Strategies for managing cancerrelated fatigue syndrome: a rehabilitation approach. Cancer. 2001; 92(4 Suppl):988-997.

14. Ling WM, Lui LY, So WK, Chan K. Effects of acupuncture and acupressure on cancer-related fatigue: a systematic review. Oncol Nurs Forum. 2014;41:581-592.

15. Oh HS, Seo WS. Systematic review and metaanalysis of the correlates of cancer-related fatigue. Worldviews Evid Based Nurs. 2011;8:191-201.

16. American Academy of Hospice and Palliative Medicine, Center to Advance Palliative Care, Hospice and Palliative Nurses Association, Last Acts Partnership, National Hospice and Palliative Care Organization. National Consensus Project for
Quality Palliative Care: Clinical Practice Guidelines for quality palliative care, executive summary. J Palliat Med. 2004;7:611-627.

17. Yennurajalingam S, Urbauer DL, Casper KL, et al. Impact of a palliative care consultation team on cancer-related symptoms in advanced cancer patients referred to an outpatient supportive care clinic. J Pain Symptom Manage. 2011;41:49-56.

18. Zweers D, de Graaf E, Teunissen SC. Nonpharmacological nurse-led interventions to manage anxiety in patients with advanced cancer: a systematic literature review. Int J Nurs Stud. 2016;56:102-113.

19. Adamsen L, Midtgaard J, Andersen C, Quist M, Moeller T, Roerth M. Transforming the nature of fatigue through exercise: qualitative findings from a multidimensional exercise programme in cancer patients undergoing chemotherapy. Eur J Cancer Care (Engl). 2004;13:362-370.

20. Brown $P$, Clark MM, Atherton $P$, et al. Will improvement in quality of life (QOL) impact fatigue in patients receiving radiation therapy for advanced cancer? Am J Clin Oncol. 2006;29:52-58.

21. Mock V. Fatigue management: evidence and guidelines for practice. Cancer. 2001;92:1699-1707.

22. Cella D, Davis K, Breitbart W, Curt G. Cancerrelated fatigue: prevalence of proposed diagnostic criteria in a United States sample of cancer survivors. J Clin Oncol. 2001;19:3385-3391.

23. Stone P, Richards M, A'Hern R, Hardy J. A study to investigate the prevalence, severity and correlates of fatigue among patients with cancer in comparison with a control group of volunteers without cancer. Ann Oncol. 2000;11:561-567.

24. National Comprehensive Cancer Network 6th Annual Conference Proceedings. March 1-4, 2001. Cancer Control. 2001; 8:10-117.

25. Spichiger E, Muller-Frohlich C, Denhaerynck K, Stoll $\mathrm{H}$, Hantikainen V, Dodd M. Prevalence and contributors to fatigue in individuals hospitalized with advanced cancer: a prospective, observational study. Int J Nurs Stud. 2012;49:1146-1154.

26. Sarhill N, Walsh D, Nelson KA, Homsi J, LeGrand S, Davis MP. Methylphenidate for fatigue in advanced cancer: a prospective open-label pilot study. Am J Hosp Palliat Care. 2001;18:187-192

27. Lindqvist $O$, Widmark $A$, Rasmussen $B H$. Meanings of the phenomenon of fatigue as narrated by 4 patients with cancer in palliative care. Cancer Nurs. 2004; 27:237-243. 